\title{
O retrato: figurações do Dr. Rodrigo Cambará e a obra de arte pictórica
}

\author{
The portrait: figurations of Dr. Rodrigo \\ Cambará and the pictorial work of art
}

Osmando J. Brasileiro ${ }^{1}$

http://lattes.cnpq.br/9581109674671578

Enviado em: 10/10/2018

Aceito em: 09/12/2018

RESUMO: O presente artigo discute a construção do duplo na personagem Dr. Rodrigo Cambará, de O retrato (1951), da trilogia O tempo e o vento, de Erico Verissimo. Essa personagem revela o seu duplo por meio de elementos constitutivos de sua identidade ou afetado por algum acontecimento externo, que ao serem expostos ao mundo ficcional revelam a dupla identidade daqueles que estão sendo representados. Destaca-se Dr. Rodrigo Cambará, em sua relação com o quadro que o representa e a repercussão causada por este e as perspectivas da arte na ficção. Nossa metodologia consiste em analisar as figurações da personagem de Erico Verissimo com base em teóricos como: Clement Rosset (1998), em O real e seu duplo; Walter Benjamin, em Magia e técnica, arte e política; em Paul Ricoeur, em Tempo e narrativa, dentre outros.

Palavras-chave: O duplo; Erico Veríssimo; Dr. Rodrigo Cambará; Figurações; Narrativa.

ABSTRACT: This article discusses the construction of the double in Dr. Rodrigo Cambara, from The Portrait (1951), from the trilogy Time and the Wind, by Erico Verissimo. This character reveals his double through constitutive elements of his identity or affected by some external event, which when exposed to the fictional world reveal the double identity of those who are being represented. It stands out Dr. Rodrigo Cambará, in his relation with the picture that represents him and the repercussion caused by this and the perspectives of the art in the fiction. Our methodology consists of analyzing the figurations of the character of Erico Verissimo based on such theoreticians as: Clement Rosset (1998), in O real and its double; Walter Benjamin, in Magic and technique, art and politics; in Paul Ricoeur, in Time and narrative, among others.

Keywords: The double; Erico Verissimo; Dr. Rodrigo Cambará; Figurations; Narrative.

\section{Introdução}

Nas últimas décadas é cada vez mais frequente e diversificado o número de produções de conhecimento e reflexões sobre a análise de textos literários. A ampliação dos programas de pós-graduação e as saídas encontradas para a crise da literatura comparada, que teve início na primeira década do século XX (WELLEK, 1994, p.108), propiciaram a criação e o uso de outras ferramentas de análise para o desempenho da metodologia comparativista da literatura. Não cabendo mais o estudo de questões superficiais, como dados biográficos do autor em relação ao personagem ou até mesmo para a compreensão da obra. Com a teoria da morte do autor, declarada por Roland Barthes em 1968 (2003), e os posteriores questionamentos sobre o que seria um autor, levantados por Michel Foucault em 1969 (2006),

\footnotetext{
${ }^{1}$ Professor Efetivo do Governo do Estado do Amapá - GEA, prof. da Faculdade de Macapá - FAMA, Doutorando em Letras UniRitter/UCS, com taxa CAPES. E-mail: osmando.brasileiro2016@gmail.com
} 
podemos considerar a afirmação de Barthes e dos questionamentos de Foucault, como algumas saídas encontradas para o problema da análise da narrativa após a crise da Literatura Comparada. Outras contribuições teóricas também colaboraram para o surgimento de novas possibilidades de análise literária de um texto já conhecido pelo leitor, como $O$ tempo e o vento, do escritor gaúcho Erico Verissimo.

Com base nesta obra, utilizando as teorias sobre o duplo ${ }^{2}$, nosso artigo analisa essa via de reflexão a partir de $O$ retrato, segunda parte da trilogia supracitada, mais precisamente com foco no personagem Dr. Rodrigo Cambará. Dessa forma, podemos entender que o processo de composição do duplo na trama narrativa acontece de várias maneiras: desde a presença de personagens com características de traços identitários que evidenciam o duplo nos personagens ou, até mesmo, por meio do choque entre o "eu" e o "outro", contido em um mesmo personagem.

Personagens ficcionais que possuem essas características podem ser encontrados em Orlando (publicado originalmente em 1928), do romance homônimo da escritora britânica Virgínia Woolf; Dorian Gray, em O retrato de Dorian Gray (1890), do escritor irlandês Oscar Wilde; e, Dr. Rodrigo Cambará, de $O$ retrato (1951), da trilogia O tempo e o vento, do escritor brasileiro Erico Verissimo. Todos esses personagens revelam o seu duplo por meio de elementos constitutivos de sua identidade ou afetados por algum acontecimento externo que, ao serem expostos ao mundo ficcional, revelam a dupla identidade daqueles que estão sendo representados. Em Dorian Gray e Dr. Rodrigo ainda temos como interface a presença da arte pictórica.

Na obra Orlando, o elemento duplo é a mudança de identidade sexual do personagem homônimo, o qual é dotado de imortalidade e, numa duração de mais de 300 anos dentro da narrativa ficcional, alterna de sexo com o passar do tempo, oscilando entre masculino e feminino; já no personagem Dorian Gray, o duplo se dá por meio do quadro que representa o protagonista e que passa a receber todos os desgastes do tempo, preservando o personagem "empírico" num pacto de "imortalidade"; Por sua vez, em Dr. Rodrigo Cambará, o duplo está representado no retrato pintado pelo artista espanhol Pepe García, cuja obraprima intrigou muitos outros personagens da ficção, causando conflito com o próprio retratado.

A partir dessas considerações preliminares, centraremos nosso estudo na construção do duplo em Dr. Rodrigo Cambará, em sua relação com o quadro que o representa (e a repercussão causada por este), verificando, também, como a arte interfere nesse processo de construção e discussão da identidade do personagem. Emprega-se, para tanto, uma metodologia interpretativa da construção do personagem romanesco e da interferência de elementos da arte nas figurações do personagem de Erico Verissimo.

No suporte teórico, nos embasamos (dentre outros pensadores) em: Clement Rosset (1998), em O real e seu duplo; Walter Benjamin, em Magia e técnica, arte e política; e em Paul Ricoeur, em Tempo e narrativa.

\section{O duplo e seus conceitos}

A trilogia de Erico Verissimo (publicados originalmente em 1949, 1951 e 1961), O tempo

\footnotetext{
${ }^{2}$ Como em Clement Rosset 2008, segundo o qual o duplo está em uma mesma pessoa, como uma espécie de reflexo da identidade e também em teorias de Walter Benjamin (1994) ao postular sobre a reprodução da obra de arte na era da reprodutibilidade técnica em que a obra de arte traz em si uma espécie de técnica que pode ser lida como "magia" na realização da obra de arte.
} 
e o vento, organizada em três partes, "O continente", "O retrato" e o "Arquipélago", respectivamente. Na segunda parte da narrativa existe uma grande mobilização em torno de um quadro pintado por Don Pepe García, um pintor espanhol radicado em Santa Fé, cidade fictícia onde acontece a maior parte da trilogia de Verissimo. O quadro acaba se tornando um símbolo de toda a narrativa por elevar o Dr. Rodrigo Terra Cambará, bisneto do Capitão Rodrigo Cambará a um dos personagens mais expoentes da trilogia, transformando o próprio quadro numa espécie de "personagem" da narrativa, por representar o "outro" da personagem Dr. Rodrigo Terra Cambará.

$\mathrm{Na}$ sociedade moderna vivemos rodeados de duplicidades. O duplo é um tema que existe desde a antiguidade e incita reflexões quando nos deparamos com situações dessa natureza, pois traz em sua construção certo estranhamento. Assim, desperta no espectador ou leitor a percepção do fato da existência dupla de um determinado elemento da natureza ou do indivíduo. Como exemplificação mais comum, podemos asseverar que não é à toa que se notam registros sobre os indivíduos gêmeos univitelinos, pois aparecem na história da humanidade cercados de simbologias e interpretações. Abrindo precedentes para fomentar considerações por parte de pensadores como Saussure (1971), que já percebia que a identidade é pautada nas diferenças e não nas semelhanças. Por extensão, essa forma de pensar atinge a literatura também.

Com o advento das tecnologias da comunicação e da informação - TICs, ficou cada vez mais fácil a veiculação de informações e a reprodução de imagens, ideias e pensamentos, culminando na multiplicação do conhecimento de forma geral. Porém, essa característica da atualidade, entra em conflito com os conceitos da obra de arte e de sua existência, por conta de uma possível aura que constituiria sua identidade (ímpar, única), impossibilitando sua reprodução ou duplicidade - pois, também envolve a questão econômica na comercialização de tais obras de arte, o que traria respaldo para a preservação de sua essência. É, portanto, necessário que se busque um conceito de originalidade e de unicidade que garantam a valorização e o respeito pela produção da obra de arte. Segundo Walter Benjamin,

Em sua essência, a obra de arte sempre foi reprodutível. O que os homens faziam sempre podia ser imitado por outros homens. Essa imitação era praticada por discípulos, em seus exercícios, pelos mestres, para a difusão das obras, e finalmente por terceiros, meramente interessados no lucro. (BENJAMIN, 1994, p.166)

Contudo, "Mesmo na reprodução mais perfeita, um elemento está ausente: o aqui e agora da obra de arte, sua existência única, no lugar em que se encontra." (BENJAMIN, 1994, p.167). O “aqui e agora” que não é possível se repetir, para Benjamin, no instante de reprodução de uma determinada obra de arte, pode, entretanto, ser verificado nessa mesma possibilidade no campo da literatura: podemos nos apoiar na filosofia aplicada à análise literária para, a partir daí, extrair outros significados.

A reprodução do instante inicial é possível segundo Paul Ricoeur (1995), pois repetese, insolitamente, nas personagens, quando elas revivem exatamente algo que aconteceu em que essa personagem se sente no retorno ao momento da primeira ação ${ }^{3}$. Há um diálogo entre esse tempo insólito e a obra de arte, pois para ela, o "aqui e agora" é exatamente o mesmo. Quando analisamos a narrativa de Verissimo (1985) é essa a sensação que temos, enquanto leitores que se engajam na leitura e no conhecimento sobre a vida da personagem,

\footnotetext{
${ }^{3}$ Essa repetição, anunciada como iteração, nos remete às próprias ideias de Benjamin, pois o termo duplo também representa multiplicar, pois quem duplica, multiplica. A arte também o faz eu seus termos ao copiar elementos da natureza e reproduzi-los como exemplos de perfeição imagética.
} 
garantindo a autenticidade e originalidade da obra de Pepe García

a na mente dos leitores e nas lembranças das personagens que têm acesso e admiram o retrato do Dr. Rodrigo.

A idealização da arte é preservada na narrativa ficcional por conta de sua garantia de existência, sempre que uma personagem tem acesso ao quadro. E o sobrado ganha, dessa forma, o status de museu: por preservar uma obra de arte que todos da cidade podem visitar e admirar. Esse espaço possui essa função na narrativa de Verissimo, e também preserva a arte na ficção com toda a sua estrutura imagética e da manutenção da aura inicial, ao mesmo tempo em que cumpre a função de valorizar e respeitar o artista, garantindo sua existência única e a manutenção da aura da obra.

Por outro lado, a especificidade e irreversibilidade do instante de criação, são fundamentais para a preservação e valorização da obra, pois,

É nessa existência única, e somente nela, que se desdobra a história da obra. Essa história compreende não apenas as transformações que ela sofreu, com a passagem do tempo, em sua estrutura física, como as relações de propriedade em que ela ingressou. (BENJAMIN, 1994, p.167).

Com essa afirmação, o pensador reforça a ideia do "aqui" e "agora" como sendo o momento original da criação da obra de arte.

Podemos pensar agora em como devemos conciliar os conceitos de duplo com os da obra de arte e podemos perceber que não é a mesma conceituação da reprodução como nos descreve Benjamin, mas possui algumas semelhanças pautadas na dualidade e na possibilidade de substituição de um objeto por outro. Assim, para Clement Rosset (2008, p.24), a noção de duplo "implica nela mesma um paradoxo: ser ao mesmo tempo ela própria e outra." Para o pensador

$\mathrm{Na}$ ilusão, quer dizer, na forma mais corrente de afastamento do real, não se observa uma recusa de percepção propriamente dita. Nela a coisa não é negada: mas apenas deslocada, colocada em outro lugar. Mas no que concerne à aptidão de ver, o iludido vê a sua maneira (ROSSET, 2008, p.17).

A partir dessa referência podemos inferir, perante a definição do duplo, que não há reprodução, o que há é um deslocamento paradoxal da coisa/objeto para outro lugar, sem necessariamente sair de onde está, ou seja, é uma duplicação com a preservação da aura do instante inicial da criação, por assim dizer. A proposta de preservação da obra de arte pictórica por meio do uso da personagem na narrativa permite a reflexão sobre os conceitos de duplo e simultaneamente, revigora a preservação da obra de arte como um todo.

O próprio Dr. Rodrigo reconhece sua essência na pintura do seu retrato, atraindo o leitor para a observação mais aprofundada do que seria uma obra de arte e seus conceitos, sem perder de vista a informação de que a personagem mantém uma personalidade dupla, tanto no quadro quanto na sua existência dentro da narrativa. Portanto, do ponto de vista da teoria do duplo, há um deslocamento da identidade de um objeto que pode ser compreendido e exemplificado por meio de uma personagem no texto narrativo. É o que veremos com a personagem Dr. Rodrigo, de $O$ retrato.

\section{0 deslocamento da identidade: o duplo em $O$ retrato, de Erico Ve- rissimo}

https://periodicos.unifap.br/index.php/letras

Macapá, v. 8, n. 3, $2^{\circ}$ sem., 2018 
A obra $O$ tempo e o vento é construída em três partes intituladas, respectivamente: "O continente", "O retrato" e "O arquipélago". Cada uma representa um período da história da família Terra-Cambará e percorre um total de 200 anos, de 1745 a 1945.

O texto narrativo traz elementos da própria construção histórica do Rio Grande do Sul e, subliminarmente 4 , também do Brasil. Em "O retrato", está contido um episódio intitulado Chantecler, que narra a história de Rodrigo Terra Cambará, um médico que possui grande poder de sedução e é muito vaidoso. $\mathrm{O}$ nome dado à personagem é por conta da homenagem que a família faz ao seu antepassado, o bisavô Rodrigo Cambará, personagem central de Um certo capitão Rodrigo, livro que está dentro de "O continente". Nesse romance, mostra-se o jovem Rodrigo Terra Cambará chegando a Santa Fé em fins de 1909 - um idealista que retorna, formado em medicina, com o intuito de revolucionar a cidade. Para isso, sua primeira empreitada é a fundação de um jornal que ele intitula de "A farpa”, instrumento que será utilizado para apoiar a candidatura de Rui Barbosa a presidente da República.

A iniciativa e a interface com os elementos históricos na narrativa servem para ligar de uma só vez a história de Santa Fé à do Brasil, sem no entanto, isolar o país do mundo. A comprovação dessa ligação do Brasil com o mundo contemporâneo à personagem está na utilização do título desse livro, "Chantecler", que faz referência a uma peça teatral daquela época, do dramaturgo francês Edmond Rostand (1868-1918), que foi estreada em Paris. A personagem principal da peça era "Chantecler", um galo imponente que se ilude achando que o sol não nasce sem o seu cantar, tal qual Rodrigo em Santa Fé, que se vê como uma figura capaz de corrigir todos os males da sua cidade natal. Por ter sido fundada por seus antepassados, aumenta ainda mais sua responsabilidade em conduzi-la rumo ao progresso. Essa construção identitária da personagem Dr. Rodrigo se dá de forma a unir a vida da personagem à própria cidade, reforçando a ligação que seus antepassados tiveram com a construção da cidade.

A figura ilustre do médico recém-formado é artisticamente imbricada com a identidade da cidade e do seu bisavô, o Capitão Rodrigo Cambará. Por isso, a finalização do quadro provoca uma certa "romaria" até o sobrado, para a apreciação da obra de arte. O retrato não é apenas uma obra de arte comum: representa a concentração e o amadurecimento do sangue dos Terra-Cambará em Santa Fé, com a participação da família na vida política, econômica e cultural da cidade.

Percebendo toda essa simbologia servia para eternizar a figura do Dr. Rodrigo, o pintor espanhol Pepe García pinta o retrato dele, que ficará na sala do sobrado. Contudo, ao concluir a obra, todos se admiram do trabalho, ao ponto de toda a cidade vir a comentar e a visitar o sobrado dos Terra-Cambará para reconhecer a obra como parte da identidade da personagem retratada e, consequentemente, inserir a obra no contexto identitário da própria cidade.

O momento de criação de uma obra de arte causa um desgaste no seu autor. Podemos verificar várias referências a esse momento da finalização de um trabalho que demandou energia e empenho de Pepe García, pois, é comum em diários e declarações de escritores e artistas a respeito disso. A produção então da obra de arte ganha proporções gigantescas no romance, e o pintor sente o desgaste causado na produção de sua obra-prima. Vejamos

\footnotetext{
${ }^{4}$ O caráter subliminar se presentifica quando percebemos que a história de formação do Rio Grande do Sul é semelhante à do própria Brasil como um todo, uma colônia formada predominantemente por pessoas que vieram da Europa e tornaram-se os donos das terras brasileiras.
} 
seu depoimento ao concluir o retrato:

- Tu não sabes nada, homem. Mas todo artista tem uma obra em que ele bota tudo que possui, sua experiência do mundo, seus sonhos, sua alma, seu gênio. E depois se queda vazio. Foi o que ocorreu comigo. Pintei o Retrato não apenas com tinta, mas com sangue e não só usei pincéis, mas também meus nervos. Pintei com paixão ${ }^{5}$. [...] O Retrato é profético, é mágico, porque dentro dele está tudo: Don Rodrigo aos vinte e quatro anos, seu passado, seus antepassados e também o futuro com todas as suas vitórias e derrotas... (VERISSIMO, 1985, p.31)

Pintar o quadro para o artista foi muito mais do que colocar cores e tons na tela. Representou a idealização e a inserção de personalidade e elementos identitários do retratado. Com todas as possibilidades imaginadas envolvendo passado, presente e futuro e usando o próprio sangue do artista, metaforicamente, enfim o quadro fica pronto.

No passado se concentram as gerações que antecederam a personagem; no presente, temos a representação do vigor e da beleza do agora com todo o seu caráter pictórico; no futuro, vitórias e derrotas são previstas, pautadas pelo passado glorioso de seus antepassados, somando-se a isso, a certeza de suas derrotas, pois todos estão sujeitos a elas. Essa predição do futuro e retomada do passado estão concentradas tanto no quadro, quanto em elementos da própria identidade da personagem retratada, pois ele possui idealizações que o ligam ao seu tempo e à sua cidade, ao mesmo tempo em que está representado no quadro pintado. Por isso, além de toda a energia utilizada na produção da obra, o que Pepe García deixou no quadro foi também o que Walter Benjamin (1994) chama de "aura" da obra, pois é o instante original da criação e que se dá como uma forma de explosão, uma única vez com cada obra de arte: é o que vai definir e conduzir para a aceitação dela como original e como obra-prima. O próprio artista reconhece o esforço e empenho dispensados no seu trabalho.

Algo semelhante, no plano da criação artística, se deu com a finalização do retrato de Dorian Gray, mas a conclusão da obra mesmo, se dá no momento da narrativa em que o protagonista olha o quadro que o retrata e faz uma espécie de pacto com o destino, por meio de um desejo que só é possível ser realizado nos contos de fadas ou nos planos da ficção: o seu desejo de se eternizar na própria duplicidade retratada, enquanto o quadro sofreria as consequências da passagem do tempo e o saldo de uma vida desregrada nas drogas, das noites sem dormir e ainda da promiscuidade sexual.

No entanto, logo no primeiro capítulo de O retrato de Dorian Gray, há uma espécie de tratado $^{6}$ sobre a arte, explicando ao leitor os motivos pelos quais a arte existe e como ela funciona, mas também tem uma explicação sobre o retrato pintado que parece com o discurso de Pepe García,

\footnotetext{
5 Assim como Pepe García, encontramos logo no início de $O$ retrato de Dorian Gray, essa necessidade que o artista sente de se dedicar ao seu trabalho, assim Basil Wallward expressa sua dedicação ao recusar a exposição de sua obra, assim como Pepe García se recusa a cobrar pelo Retrato de Rodrigo "mas realmente não posso exibi-lo. Coloquei muito de mim mesmo nele." (WILDE, 2012, p.15)

${ }^{6}$ Não podemos subestimar o narrador em pensar que esse tratado é algo solto, pois é uma demonstração e esclarecimento ao leitor do comprometimento que a narrativa desdobra por meio da arte, assim como em Benjamin que fica claro que quem multiplica reproduz, há também, em ambos os retratos a mensagem da força imagética que atinge o apreciador da obra de arte. Também encontramos uma espécie de tratado da arte em $O$ Retrato, mencionado pelo narrador e por Pepe García que falam sobre os objetivos da arte. Todo essa estratégia tem finalidade narrativa de inserir o leitor na proposta do narrador com suas personagens, trazendo-o para o jogo da leitura, esclarecendo as regras e ficam claras, nas obras estudadas, que o duplo vai surgir por intermédio da arte.
} 
Cada retrato que é pintado com sentimento é um retrato do artista, não do modelo. O modelo é apenas uma circunstância, uma ocasião. Não é ele que é revelado pelo artista; pelo contrário, é o artista que, em uma tela cheia de cores, revela a si mesmo. O motivo pelo qual não exibirei este retrato é que temo mostrar com ele o segredo de minha alma. (WILDE, 2012, p.17)

Fica na obra do artista um pouco de sua identidade, assim o duplo se revela (ISSN 2238-8060) também para o artista que pinta e não apenas para o modelo/personagem pintada. O duplo em Dorian Gray se dá de forma diferente do que em Dr. Rodrigo.

Para Dorian Gray, o desejo é atendido e, a partir daquele momento da narrativa, o tempo passa para todos, menos para ele. Temos assim, em Oscar Wilde (2012) uma representação da ideia de que as artes podem dar ao homem a imortalidade. As academias de letras são o templo dessa suposta imortalidade, mas, além disso, o quadro revela que Dorian Gray possui um duplo, que é sua alma aprisionada no quadro - uma prisão que só a morte do corpo é capaz de libertar. Por seu turno, no retrato de Dr. Rodrigo, sua eternização se dá na pintura que preserva suas características físicas e mantém sua identidade.

Após a admiração do autor do retrato e a entrega da obra ao dono, o artista não cobra nada pela pintura, pois ele acredita que a obra de arte não é para ser vendida. Acha, portanto, uma ofensa sua comercialização. Após o descerramento do pano que cobria o retrato e inicia sua apresentação ao público, o próprio Dr. Rodrigo encontra-se admirando a si mesmo refletido no retrato. Nesse momento, quando seu duplo se evidencia, o quadro se torna uma janela, para, nos momentos mais difíceis, ele se refugiar na imagem de si mesmo e buscar alívio para os problemas do seu dia a dia político e emocional, foge dos problemas e tem refúgio do seu pensamento refletindo sobre si mesmo.

O retrato de autoria de Pepe García possui peculiaridades especiais na narrativa. Como disse o pintor, retrata as glórias do passado e as derrotas do futuro. Demonstrando o poder da visão da arte. O artista é aquele que vê o futuro e reconhece sua vertente profética, mencionada desde pensadores da antiguidade clássica grega, como Aristóteles e Platão. O pintor de Dr. Rodrigo depõe,

Vi tudo em meus olhos, como vi o futuro de Rodrigo, quando pintei o Retrato. Está tudo lá no quadro. Vai ver. Tudo: a glória, sua carreira, suas viagens, a Revolução de 30, o Estado Novo, as mulheres que ele amou, e também este final desastroso... [...] - É um retrato profético. (VERISSIMO, 1985, p. 32)

A consciência de Pepe García está também atenta ao mundo dos artistas. Sua forma de pensar vai contra a reprodutibilidade técnica, uma vez que a máquina não é capaz de captar a aura ou "alma" da obra de arte: uma fotografia portanto é uma imagem morta, diferente do quadro pintado. Sobre esta forma de arte, assim nos fala Walter Benjamin, citado Regina da Costa da Silveira,

Com a fotografia, o valor do culto começa a recusar [...] Mas o valor de culto não se entrega sem oferecer resistência. Sua última trincheira é o rosto humano. Não é por acaso que o retrato era o principal tema das fotografias. O refúgio derradeiro do valor do culto foi o culto da saudade. [...]. A aura acena pela última vez na expressão de um rosto, nas antigas fotos. (2005, p.47)

Sendo Pepe García um pintor que briga veementemente contra as máquinas, ao ver as fotos de Dr. Rodrigo, tiradas em Porto Alegre durante sua estada na capital do Estado, se sente na obrigação de pintar um retrato para provar que as fotos não possuem alma; e não cobrar por isso demonstra o seu compromisso em respeitar e manter a arte na obra. $\mathrm{O}$ 
artista luta contra as fotografias porque observa nelas a ausência da vida, da "aura", tão importante ao objeto de arte. Assim, "O inconformismo e a rebeldia do pintor diante da reprodução técnica, mecânica e 'sem alma' da imagem de Rodrigo leva o pintor a irromper no Sobrado, certa tarde, levando consigo grande tela e cavalete." (SILVEIRA, 2005, p.48). Foi naquele momento da narrativa que o pintor espanhol então iniciou sua pintura, a qual levou vários dias para ficar pronta, mas que causou uma reação espantada ao retratado. $\mathrm{O}$ desafio feito o converteu em vencedor. $\mathrm{O}$ narrador assim descreve a entrega do retrato:

- Prepárate, Rodrigo. O pintor começou a desenrolar com mãos nervosas os panos que envolviam o quadro. Ao ver a própria imagem na tela, Rodrigo sentiu como que um soco no plexo solar. Por um momento a comoção dominou-o, embaciou-lhe os olhos, comprimiu-lhe a garganta, alterou-lhe o ritmo do coração. Quedou-se por um longo instante a namorar o próprio retrato. Ali estava, nas cores mesmas da vida, o Dr. Rodrigo Cambará, todo vestido de preto, [...], a mão esquerda metida no bolso dianteiro das calças, a direita a segurar o chapéu-coco e a bengala. O sol tocava-lhe o rosto. O vento revolvia os cabelos. E havia no semblante do moço do Sobrado um certo ar de altivez, de sereno desafio. Era como se - dono do mundo - olhos cheios duma apaixonada confiança em si mesmo e na vida. (VERISSIMO, 1985, p. 354-355)

É de grande impacto o contato de Rodrigo com seu duplo. A obra construída por Pepe García é sedutora até mesmo para o próprio retratado, que fica estático diante de si mesmo e da imponência da pintura. Não é difícil compreender, depois disso, os motivos pelos quais toda a cidade de Santa Fé apareceu para apreciar o quadro pintado por Don Pepe. O quadro deixa de ser apenas um retrato e é evidenciado como o duplo de Rodrigo e também habitante da cidade.

\section{Considerações finais}

Os duplos são também formas de alternância entre realidade e fuga por meio da ilusão. Como asseverou Clement Rosset, o quadro é o momento de fuga do Dr. Rodrigo diante dos problemas políticos e dos momentos de derrota previstos pelo próprio Pepe García e confirmados pelo andamento da narrativa de Erico Verissimo, como o leitor pode notar quando a história se reporta ao momento da morte da filha da personagem (Alice). Naquele instante, ele vê-se compelido a rasgar o próprio diploma, por sentir-se incapaz de curar sua própria filha. Assim, sua identidade se une ao quadro para chorar mais essa derrota sofrida, imposta pela vida.

O quadro na ficção de Verissimo é uma espécie de "pasárgada", como aquela construída por Manuel Bandeira em sua poesia, que serve de fuga para a personagem.

O Retrato se tornou uma espécie de obra de arte em que não apenas o seu autor, Pepe García, ia visitar para se recompor, mas também tornou-se objeto de curiosidade de toda os moradores da cidade. Foram muitos os que visitaram o casarão apenas para admirar a grande obra-prima de Don Pepe, como o chamavam os amigos, em que, acima de qualquer coisa, revelou o duplo e toda a vaidade do Dr. Rodrigo, por meio de uma insólita composição de sua imagem feita a sangue e nervos do artista, a qual condensa o caráter pictórico da arte e da vida na alma do retratado. 


\section{REFERÊNCIAS}

BANDEIRA, Manuel. Bandeira de bolso: uma antologia poética. Porto Alegre: L\&PM, 2008. (Organização e apresentação de Mara Jardim).

BARTHES, Roland. O Rumor da língua. Lisboa: Edições 70, 2003.

BENJAMIN, Walter. A obra de arte na era de sua reprodutibilidade técnica. In:

Magia e técnica, arte e política: ensaios sobre literatura e história da cultura. 7 . ed. trad. de Sergio Paulo Rouanet. São Paulo: Brasiliense, 1994.

FOUCAULT, Michel. O que é um autor? Trad. António F. Cascais e Eduardo Cordeiro. $6^{a}$ ed. Lisboa: Nova Vega, 2006.

RICOEUR, Paul. Tempo e narrativa. Tradução de Roberto Leal Ferreira. Campinas: Papirus, 1997. t. III.

ROSSET, Clement. O real e seu duplo: ensaio sobre a ilusão. Trad. José Thomaz Brum. 2. ed., revista. Rio de Janeiro: José Olympio, 2008.

SAUSSURE, Ferdinand de. Curso de linguística geral. 3. ed. tradução de Antônio Chelini, José Paulo Paes e Izidoro Blikstein. São Paulo: Cultriz, 1971.

SILVEIRA, Regina da Costa da. O pintor d'O retrato e o Oleiro d'A caverna na era da reprodutibilidade Técnica da obra de arte. In: Dossiê Erico Verissimo. Nonada: letras em revista, ano 8, n. 8, 2005. p. 45-56.

VERISSIMO, Erico. O retrato. 5. ed. São Paulo: Círculo do Livro S. A., 1985.

WELLEK, René. A crise da literatura comparada. In: COUTINHO, Eduardo F. e CARVALHAL, Tania Franco (orgs.) Literatura comparada: textos fundadores. Rio de Janeiro: Rocco, 1994. (p.108-119).

WILDE, Oscar. O retrato de Dorian Gray. São Paulo: Landmark, 2012.

WOOLF, Virginia. Orlando. $2^{a}$ ed. Tradução Cecília Meireles. Rio de Janeiro: Nova Fronteira, 2003. 